Interest in and understanding of epilepsy have never been greater than at present and, with the rapid development of knowledge of the molecular biology and neurochemical mechanisms underlying epilepsy, it is likely that research will provide more effective and safer drugs in the near future.

N V O'DONOHOE

Department of Paediatrics,

(Trinity College),

National Children's Hospital,

Harcourt Street,

Dublin 2,

Republic of Ireland

1 Dodson WE. Special pharmacokinetic considerations in children. Epilepsia 1987;28 (suppl 1):S56-70.

2 Commission on Classification and Terminology of the International League Against Epilepsy. Proposal for revised classification of epilepsies and epileptic syndromes. Epilepsia 1989;30:389-99.

3 O'Donohoe NV. The epilepsies. In: Eyre J, Boyd R, eds. Paediatric specialty practice for the 1990s. London: Royal College of Physicians, 1991:51-63.

4 Abu-Arafeh IA, Wallace SJ. Unwanted effects of antiepileptic drugs. Dev Med Child Neurol 1988;30:117-20.

5 Taylor DC, McKinlay I. When not to treat epilepsy with drugs. Dev Med Child Neurol 1984;26:822-33.

6 Freeman JM. A clinical approach to the child with seizures and epilepsy. Epilepsia 1987;28(suppl 1):S103-7.

7 Beaussart M, Faou R. Evolution of epilepsy with rolandic paroxysmal foci. A study of 324 cases. Epilepsia 1978;19:333-42.

8 Addy DP. Phenobarbitone and febrile convulsions. Arch Dis Child 1990;65: 921.

9 Hirtz DG, Ellenberg JH, Nelson KB. The risk of recurrence of non-febrile seizures in children. Neurology 1984;34:637-41.

10 Camfield P, Camfield C, Dooley J, Tibbles J, Fung T, Garner B. Epilepsy after a first unprovoked seizure in childhood. Neurology 1985;35:1657-60.

11 Reynolds EH. The process of kindling: is kindling relevant? In: Bolwig TG Trimble MR, eds. The clinical relevance of kindling. Chichester: John Wiley
1989:149-60.

12 de Silva M, McArdle B, McGowan M, Reynolds EH, Neville B, Johnson AL. Monotherapy for newly diagnosed childhood epilepsy. A comparative tria and prognostic evaluation. Epilepsia 1989;30:662.

13 Shinnar S, Vining EPG, Mellits EM, et al. Discontinuing antiepileptic medication in children with epilepsy after two years without seizures. $N E n g l$ cation in children with

14 Matricardi M, Brinciotti $\dot{M}$, Benedetti P. Outcome of discontinuation of antiepileptic drug treatment in children with epilepsy. Epilepsia 1989;30:582-9. epileptic drug treatment in children with epilepsy. Epilepsia 1989;30:582-9. Schmidt D. Adverse effects of anti-ep
$\mathcal{F}$ Med 1989;56(suppl, part 1):S132-9.

16 Rowan AJ, Meijer JWA, De-Beer Pawlikowski N, Van Der Geest P, Meinardi $\mathrm{H}$. Valproate-ethosuximide combination therapy for refractory absence seizures. Arch Neurol 1983;40:797-802.

17 Callaghan N, Goggin T. Ádjunctive therapy in resistant epilepsy. Epilepsia 1988;29(suppl 1):S29-35.

18 Wallace SJ. Antiepileptic drug monitoring. An overview. Dev Med Child Neurol 1990;32:923-6.

19 Trimble MR. Anticonvulsant drugs: mood and cognitive function. In: Trimble MR, Reynolds EH, eds. Epilepsy, behaviour and cognitive function. Chichester: John Wiley, 1988: 135-43.

20 Gallasi R, Mooreale A, Lorusso S, Rocaccianti G, Lugaresi E, Baruzzi A. Cognitive effects of valproate. Epilepsy Res 1990;5:160-4.

21 Sussman NM, McLain LW. A direct hepatotoxic effect of valproic acid. $7 A M A$ 1979;242:1173-4.

22 Brown JK. Valproate toxicity. Dev Med Child Neurol 1988;30:121-5.

23 Appleton RE, Farrell K, Applegarth DA, Dimmick JE, Wong LTK, Davidson AGF. The high incidence of valproate hepatotoxicity in infants may relate to familial metabolic defects. Can f Neurol Sci 1990;17:145-8.

24 Dreifuss FE, Langer DH, Moline KA, Maxwell JE. Valproic acid hepatic fatalities. II. US experience since 1984. Neurology 1989;39:201-7.

25 Dreifuss FE, Langer DH. Hepatic considerations in the use of antiepileptic drugs. Epilepsia 1987;28(suppl 2):S23-9.

26. Snead OC, Hosey LC. Exacerbation of seizures in children by carbamazepine. N Engl Y Med 1985;313:916-21.

27 Brodie MJ, Porter RJ. New and potential anticonvulsants. Lancet 1990;336: 425-6.

28 Reynolds EH. Vigabatrin. Rational treatment for chronic epilepsy. BMF 1990;300:277-8.

29 Luna D, Dulac O, Pajot N, Beaumont D. Vigabatrin in the treatment of childhood epilepsy. A single-blind placebo-controlled study. Epilepsia 1989;30:430-7.

30 Jawad S, Richens A, Goodwin G, Yuen WC. Controlled trial of lamotrigine (Lamictal) for refractory partial seizures. Epilepsia 1989;30:356-63.

31 Court D, Alberman E. Worlds apart. In: Forfar JO, ed. Child health in a changing society. Oxford: Oxford University Press foi the British Paediatric Association, 1988:1-30.

\title{
Transoesophageal echocardiography: a new diagnostic method in paediatric cardiology
}

Over the past decade cardiac ultrasound techniques have revolutionised the practice of paediatric cardiology. Transthoracic cross sectional imaging allows for an accurate and non-invasive assessment of intracardiac morphology in the vast majority of children. Doppler ultrasound techniques provide a detailed insight into the related haemodynamic changes of congenital cardiac lesions.

Transoesophageal echocardiography has become an established diagnostic and monitoring technique in adult cardiology. ${ }^{1}$ An ultrasound transducer, mounted at the tip of a flexible endoscope, is introduced into the oesophagus and echocardiographic studies can be performed without interference of either the thoracic cage or lung tissue. This produces high quality images in every patient studied. Some two years ago, miniaturised transoesophageal probes were developed, ${ }^{2}$ which allow studies to be carried out in even small children. ${ }^{34}$ However, what are the advantages and what are the relative contributions of transoesophageal studies in children with congenital heart disease? Do we need a further diagnostic and monitoring technique?

Over a two year period more than 240 transoesophageal studies have been performed at the Sophia Childrens Hospital, Rotterdam, the Netherlands and the Royal Hospital for Sick Children, Edinburgh, Scotland. The results of these studies were reviewed to determine the role of paediatric transoesophageal studies in different clinical settings. All transoesophageal studies were carried out under either general anaesthesia (given in the majority of cases for either cardiac catheterisation or cardiac surgery) or heavy sedation. Antibiotic endocarditis prophylaxis was not administered in any patient, and no episode of bacterial endocarditis was observed. Complications were encountered in three children (1.2\%). These included arrhythmias in two. Oesophageal bleeding was encountered in only one patient. No death occurred.

\section{Primary diagnosis of congenital heart disease}

When compared with transthoracic echocardographic studies, the transoesophageal ultrasound approach provides a more detailed evaluation of the morphology of the atrial chambers. The visualisation of both atrial appendages, for the first time, allows the direct diagnosis of atrial situs ${ }^{5}$ and the definite preoperative documentation of juxtaposed atrial appendages. ${ }^{6}$ The morphology and integrity of the atrial septum is frequently better assessed by transoesophageal studies. Superiorly located defects, such as sinus venosus atrial septal defects, can be visualised in much greater 
detail. Multiple atrial septal defects can be identified with ease. In addition, the borders of any defect can clearly be defined, as can be the presence of any tissue flap of the oval fossa that may partially cover the defect. These detailed insights to be obtained by transoesophageal studies may be anticipated to have major implications on a refined patient selection for transcatheter atrial septal defect closure.

Anomalies of either the systemic or pulmonary venous return are much more readily diagnosed by transoesophageal than by transthoracic echocardiographic studies. ${ }^{7}$ The individual sites of connection of all four pulmonary veins can be documented in $93 \%$ of the cases, thus providing a most sensitive tool in the preoperative exclusion of anomalous pulmonary venous connections. When compared with angiocardiography, the technique provides additional morphological information on the site of venous connections relative to the atrial septum. Thus in children with this range of lesions transoesophageal studies are highly beneficial in the preoperative diagnosis. In older children with complex congenital heart disease, involving the atrioventricular junction of the heart, transoesophageal studies constitute an important adjunct in the preoperative diagnosis. ${ }^{8}$ Major contributions include the exclusion of chordal straddling and the definition of the valvar and subvalvar anatomy (figure). Transoesophageal studies should be considered to be essential in all children in whom a septation procedure is considered.

In children with their generally good transthoracic ultrasound windows, relatively little additional information is gained by transoesophageal studies on either the ventricular chambers, the ventriculoarterial junction, or the great arteries. The only exception is a more detailed assessment of the morphology of the range of lesions producing left ventricular outflow obstruction in childhood.

Monitoring of surgery and interventional catheterisation Transoesophageal studies can be used effectively in the monitoring of cardiac operations. The surgical results can be documented and the majority of residual lesions can be identified immediately. 9 However, intraoperative transoesophageal studies are limited when compared with direct epicardial ultrasound studies, ${ }^{10}$ which provide higher resolution imaging and an unlimited range of imaging planes. The major implications of transoesophageal studies would appear to lie in the diagnosis and management of early postoperative complications, when praecordial imaging is frequently impossible.

During interventional cardiac catheterisation transoesophageal studies proved to be a versatile real time imaging and monitoring technique. Studies can be performed without either interference or prolongation of the procedure. Potential complications can be detected immediately, and the immediate haemodynamic changes can be assessed. In addition, the technique is of value in monitoring and guiding guidewire and catheter placement for example across the atrioventricular valves or within a Mustard baffle. Although the total number of patients who had transoesophageal monitoring during interventional cardiac catheterisation is still limited to date, it may be anticipated that the technique may help to reduce the amount of radiation and contrast agent required. The monitoring of atrial septal defect closure is a further indication for transoesophageal studies in children. ${ }^{11}$ In fact, the technique appears to be a prerequisite for a high success rate with this new therapeutic approach.

\section{Long term follow up of congenital heart disease}

After cardiac surgery via a sternotomy, scar tissue formation often limits transthoracic ultrasound studies. In contrast, the transoesophageal approach remains unrestricted. Much improved diagnostic insights can be gained in particular on lesions or surgical repair involving either venous return, the atrial chambers, or the atrioventricular junction. The advantages of transoesophageal studies in this patient population include a more detailed assessment of native or prosthetic atrioventricular valve dysfunction or endocarditis
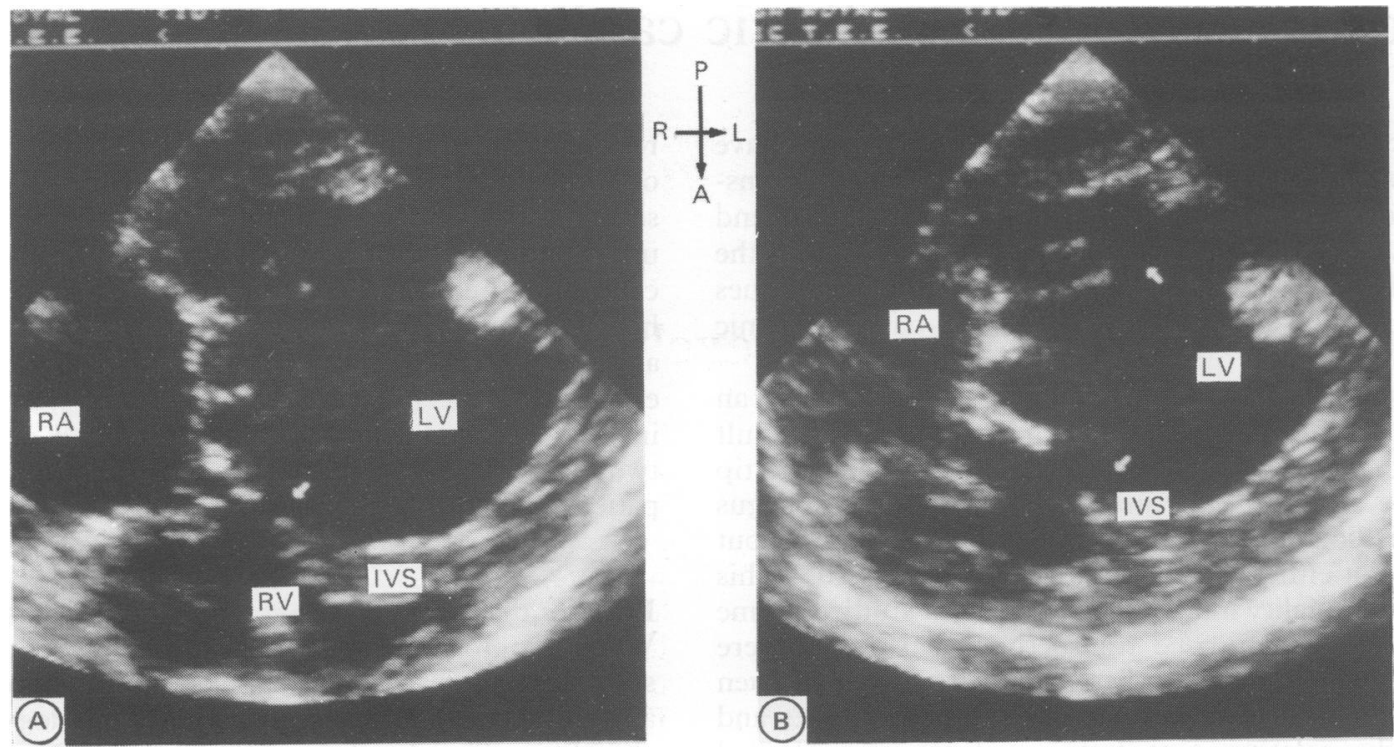

Transesophageal visualisation of an overriding and straddling right atrioventricular valve (tricuspid valve) in a $13 \mathrm{~kg}$ boy who was previously diagnosed of having severe tetralogy of Fallot. (A) Scanning of the inferior portion of the right atrium and the ventricular chambers demonstrates appreciable overriding of the tricuspid valve over a rudimentary ventricular septum. The right ventricular cavity is of diminutive size, whereas the left ventricle is enlarged. Chordal attachments of the anterior leaflet of the tricuspid valve are seen to insert into the the crest of the ventricular septum (arrow). (B) The inferior leaflet of the attachments of the anterior leaflet of the tricuspid valve are seen to insert into the the crest of the ventricular septum (arrow). (B) The inferior leaflet of the
tricuspid valve is almost exclusively attached to the left ventricular chamber (arrows). The diagnosis was changed into double inlet left ventricle. The pattern of chordal attachments of either atrioventricular valve, as documented on transoesophageal imaging, precluded a biventricular repair. A=anterior, IVS = interventricular septum, $L=$ left, $L V=$ left ventricle, $P=$ posterior, $R=$ right, $R A=$ right atrium, $R V=$ right ventricle. 
Indications for transoesophageal studies in children

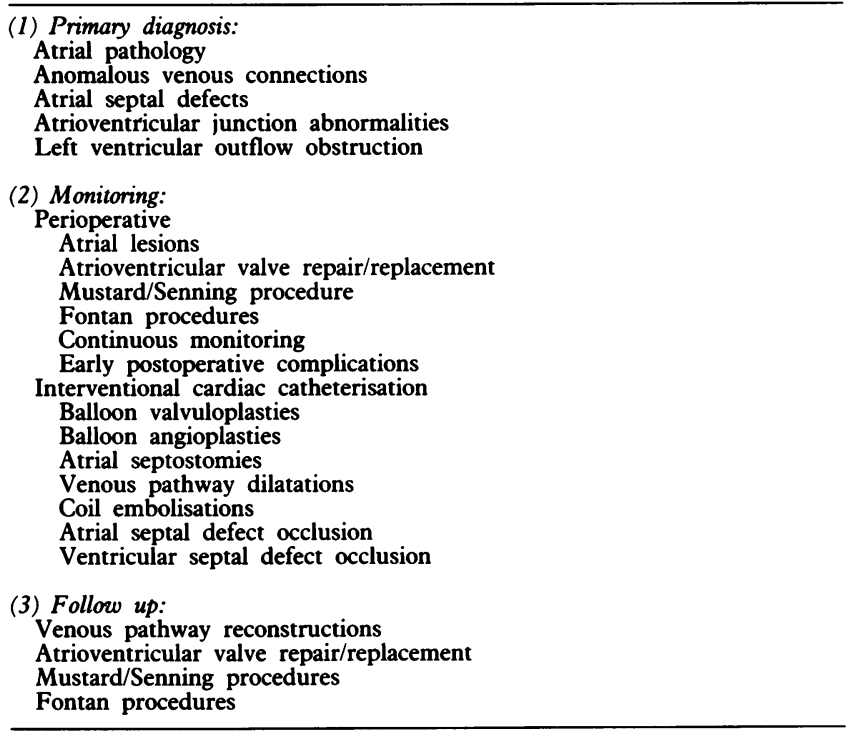

lesions. After the Mustard or Senning procedure for complete transposition, transoesophageal studies allow a complete evaluation of atrial baffle function, ${ }^{12}$ and thus largely influence the need for follow up cardiac catheterisation. After the various modifications of the Fontan procedure, which is used for palliation of a range of complex congenital cardiac lesions, the transoesophageal ultrasound approach provides a most sensitive tool in the definition of residual or acquired haemodynamic lesions and yields new insights into the patterns of the pulmonary circulation. ${ }^{13}$

\section{Limitations}

Paediatric transoesophageal echocardiography is a semiinvasive technique that requires either general anaesthesia or heavy sedation. Thus appropriate patient selection is mandatory (table). With the currently available dedicated paediatric scanning equipment studies in children below 4 $\mathrm{kg}$ in weight should be performed only if the information likely to be obtained is of importance for appropriate patient management. The present probe technology allows for only single plane imaging of the heart, thus making transoesophageal scanning a strictly tomographic technique. However, it is likely that biplane ${ }^{14}{ }^{15}$ or multiplane paediatric transoesophageal probes will be designed in the near future and will further increase the range of diagnostic insights to be obtained.

\section{Conclusion}

Transoesophageal echocardiography is a relatively new adjunct to the ultrasound evaluation of congenital cardiac lesions. It is a safe, albeit semi-invasive, technique that rapidly has gained a well defined place in the diagnostic armamentarium of the paediatric cardiologist.

Department of Paediatric Cardiology,

OLIVER STÜMPER

Royal Hospital for Sick Children,

Sciennes Road,

Edinburgh EH9 ILF

1 Gussenhoven EJ, Taams MA, Roelandt JRTC, et al. Transoesophageal twodimensional echocardiography: its role in solving clinical problems. $\mathcal{F} \mathrm{Am}$ Coll Cardiol 1986;8:975-9.

2 Kyo S, Koike K, Takanawa E, et al. Impact of transoesophageal Doppler echocardiography on pediatric cardiac surgery. Int $\mathcal{f}$ Card Imaging 1989;4: 41-2.

3 Ritter Sb, Hillel Z, Narang J, Lewis D, Thys D. Transesophageal real time Doppler flow imaging in congenital heart disease: experience with the new pediatric transducer probe. Dynamic Cardiovascular Imaging 1989;2:92-6.

4 Stümper O, Elzenga NJ, Hess J, Sutherland GR. Transesophageal echocardiography in children with congenital heart disease-an initial experience. f Am Coll Cardiol 1990;16:433-41.

5 Stümper O, Sreeram N, Elzenga NJ, Sutherland GR. The diagnosis of atrial situs by transoesophageal echocardiography. $\mathcal{J}$ Am Coll Cardiol 1990;16: 442-6.

6 Stümper O, Rijlaarsdam M, Vargas-Barron J, Romero A, Hess J, Sutherland GR. The assessment of juxtaposed atrial appendages by transoesophageal echocardiography. Int $\mathcal{f}$ Cardiol 1990;29:365-71.

7 Stümper $\mathrm{O}$, Vargas-Barron J, Rijlaarsdam $\mathrm{M}$, et al. The assessment of anomalous systemic and pulmonary venous connections by paediatric anomalous systemic and pulmonary venous connections by paediat

8 Sreeram N, Stümper O, Kaulitz R, et al. The comparative value of surface and transesophageal ultrasound in the assessment of congenital abnormaand transesophageal ultrasound in the assessment of congenital abnorma-
lities of the atrioventricular junction. $₹ \mathrm{Am}$ Coll Cardiol 1990;16:1205-14.

9 Roberson D, Muhiudeen I, Silverman N, Turley K, Cahalan M. Intraoperative transoesophageal echocardiography in infants and children with cardiac shunt lesions. F Am Soc Echocardiogr 1990;3:213.

10 Stümper O, Kaulitz R, Sreeram N, et al. Intraoperative transesophageal versus epicardial ultrasound in surgery for congenital heart disease. $\mathcal{f} \mathrm{Am}$ Soc Echocardiogr 1990;3:392-401.

11 Hellenbrand WE, Fahey JT, McGowan FX, Weltin GG, Kleinman CS. Transoesophageal echocardiographic guidance of transcatheter closure of atrial septal defect. Am $\mathcal{F}$ Cardiol 1990;66:207-13.

12 Kaulitz R, Stümper $\mathrm{O}$, Geuskens $\mathrm{R}$, et al. The comparative values of the precordial and transoesophageal approaches in the ultrasound evaluation of atrial baffle function following an atrial correction procedure. $\mathcal{f} \mathrm{Am}$ Coll Cardiol 1990;16:686-94.

13 Stümper O, Sutherland GR, Geuskens R, Roelandt JRTC, Bos E, Hess J. Transoesophageal echocardiography in evaluation and management of the Fontan circulation. $\mathcal{f} \mathrm{Am}$ Coll Cardiol 1991;17:1152-60.

14 Omoto R, Kyo S, Matsumura M, et al. Biplane color transoesophageal Doppler echocardiography (color TEE): its advantages and limitations. Int f Card Imaging 1989;4:57-8.

15 Stümper O, Fraser AG, Ho SY, et al. Transoesophageal echocardiography in the longitudinal axis: correlation between anatomy and images and its clinical implications. Br Heart f 1990;64:282-8.
The majority of infants with biliary atresia in the UK are still being referred too late to get optimal benefit from the operation of portoenterostomy. It is now 14 years since we first reported the importance of early referral in this journal. ${ }^{1}$ The success of early surgery has been reported repeatedly since then. Over $80 \%$ of infants with biliary atresia who underwent surgery before 60 days of age have become jaundice free, compared with $20-35 \%$ for those with later surgery. ${ }^{2}$ Results of surgery are less satisfactory in centres operating on few cases. ${ }^{3}$ It was clear even 14 years ago that infants who cleared their jaundice had a good prospect of long term survival with a good quality of life. ${ }^{1}$ This has been confirmed in the last few years from Japan and Europe. ${ }^{4}$ A 15 year survival of $87 \%$ has been reported in infants who become jaundice free. ${ }^{5}$ The age at portoentero- stomy dictates the frequency of survival beyond 10 years of age. For example in one series 17 of $26(73 \%)$ infants operated by 60 days of age survived to 10 years as compared with only eight of $71(11 \%)$ operated after 90 days of age. Thirty of 48 aged from 10 to 33 years have had a completely uncomplicated course while 37 are leading normal lives with no current medical or surgical problems. ${ }^{6}$ Reports from France are similar with the most satisfactory outcome in those operated on by 45 days of age. ${ }^{7}$ Preliminary analysis of patients treated since 1973 at King's College Hospital suggest a similar outcome but few were treated before 45 days.

These observations on the outcome of early surgery are in keeping with what is known of the pathology of biliary atresia. ${ }^{8}$ In the extrahepatic biliary tract there is a pro- 